\title{
Dziedzictwo miejskie Krakowa, czyli rzecz o ksiażce Mapy miasta. Dziedzictwa i sacrum w przestrzeni Krakowa
}

\author{
The urban heritage of Krakow, or about the book \\ Maps of the City. Heritages and the Sacred \\ within Kraków's City Scape
}

W milenijnym roku 2000, w ramach obchodów brytyjskich uroczystości narodowych nowego tysiąclecia, zrealizowano projekt - jak relacjonuje Tim Edensor - polegający na prostym sondażu przeprowadzonym wśród wielotysięcznej grupy klientów sklepów Mark and Spencer, którego celem była odpowiedź na pytanie: „Co twoim zdaniem najlepiej reprezentuje Wielką Brytanię i dlaczego? Podaj jeden przykład”. Z tysięcy odpowiedzi wybrano czterysta najczęściej powtarzających się, pośród których - by wymienić tylko kilka - znajdują się: rodzina królewska i Union Jack, czerwone budki telefoniczne i czarne taksówki, Beatlesi i James Bond (Edensor 2004: 226-236).

Oczywiście, można sobie wyobrazić analogiczną sondę dotyczącą najlepszej reprezentacji Krakowa, a bardziej precyzyjnie - dziedzictwa Krakowa. Anna Niedźwiedź i Kaja Kajder, redaktorki książki Mapy miasta. Dziedzictwa i sacrum w przestrzeni Krakowa. Maps of the City. Heritages and the Sacred within Kraków's City Scape (Niedźwiedź, Kajder 2020), która nawiązuje do wystawy w Muzeum Etnograficznym o tym samym tytule z przełomu lat 2017/2018, nie pomijają zatem takich wskazań, jak smok wawelski, pejzaże miejskie z Rynkiem, Plantami, Bramą Floriańską, obwarzanek, Lajkonik, figurki żydowskich grajków, krakowiak i krakowianka... Rychło jednak 
porzucają tę wyrywkową wyliczankę wiedzione - wydaje się - potrzebą skupienia się nie na niemej ilości, a zawężonej, jednak wiele mówiącej jakości - eksponującej detal, niepowtarzalne i wieloznaczne treści i wartości, z których wyłania się genius loci miasta. Takie jakościowe kwalifikacje to nie przypadkiem wyróżniki podejścia antropologicznego, które wskazują na niemal obsesyjne przywiązanie badacza do szczegółów badanej rzeczywistości, nie wyłączając tej materialnej, która tylko pozornie wydaje się niema. W istocie bowiem pod skupionym okiem antropologa ujawniają się liczne niuanse, wieloznaczności, konteksty, a wtedy w pewien swoisty sposób owa materia zaczyna przemawiać. Mowa ta, wprawdzie nieuchronnie pochodząca z przeszłości, możliwa jest jednak do uchwycenia dziś, choć niedoskonałego, zniekształcającego, oddającego jednak coś więcej, co wykracza poza utarte pojęcia ogólne, taksonomie, kategoryzacje. Przekaz przybywający z owej przeszłości, podany z użyciem „mowy obiektów materialnych", pozwala na uchwycenie choćby widmowego jej śladu, jednak bardziej działającego na wyobraźnię niż wyabstrahowana ze zmysłowego doświadczania świata narracja źródeł historycznych. Dotyczy to zresztą wszelkich etnograficznych narzędzi badawczych, zaabsorbowanych wprawdzie głównie teraźniejszością niż przyszłością. Wszelako - jak utrzymuje David Lowenthal (2013) -przeszłość jest również przypadkiem obcości kulturowej, wprawdzie nie w perspektywie synchronicznej, lecz diachronicznej. Jules Prown zauważa przy tej okazji:

Dokonując interpretacji kulturowej poprzez artefakty, wchodzimy w tym przypadku w kontakt z inną kulturą nie poprzez nasze umysły, w których zakorzenione są nasze „uprzedzenia”, lecz poprzez zmysły. Przenośnie rzecz ujmując, wchodzimy w skórę jednostek, które wytwarzały lub użytkowały rzeczy; możemy wówczas widzieć ich oczami i dotykać ich rękami. Nie ma wątpliwości, że empatyczne utożsamienie się poprzez zmysły z ludźmi z przeszłości lub z innych miejsc jest czym innym, niż wchodzenie z nimi w kontakt poprzez czytanie napisanych słów. Zamiast naszych umysłów nawiązujących kontakt intelektualny z ich umysłami, nasze zmysły wchodzą w afektywny kontakt z ich doświadczeniem zmysłowym (Prown 2000: 26).

Czasem wystarczy zatem pewien wspólny mianownik zmysłów, łączący do pewnego stopnia epoki i społeczeństwa, by uchwycić najważniejsze elementy podzielanego świata. Ten etnograficzny, jakościowy i zmysłowy rys omawianej książki ujawnia się również w skupieniu głównie na bardzo konkretnym fragmencie dziedzictwa miasta, obszarze Traktu Królewskiego, fragmencie jednak historycznie szczególnym, bo sięgającym okresu głębokiego średniowiecza. To cena zawężenia, którą często warto zapłacić, tracąc wprawdzie na efekcie ilości, zyskując za to na jakości przedstawienia świata, który ujawnia swe detale i osobliwości niczym przez okular mikroskopu. Zdaje się wręcz sam przemawiać wielogłosem znaczeń, wartości, emocji zaludniających go kolejnych pokoleń krakowian. Same przedmioty nieożywione - od pojedynczych 
kamieni nadgryzionych przemijającym czasem, po okazałe budowle -przemawiają mową własną form i funkcji, odsyłając wciąż do czasu osuwającego się w przeszłość. Autorstwo antropologów nie jest tutaj bez znaczenia - tego typu podejście jest znakiem firmowym dyscypliny wiedzy, która opisuje i interpretuje rzeczywistość przez pryzmat ludzkich przekonań, wartości i emocji, mających wszak tendencję do krzepnięcia w postać zróżnicowanych wyobrażeń zbiorowych, które stanowią fundament dla całego gmachu zmieniającej się w czasie kultury.

Tytułowe mapy, które stanowią tyleż przestrzenny, co mentalny horyzont rozumienia i doświadczania miasta, składają się z traktów historii, jak ów główny - Trakt Królewski, i nawarstwionych na nich ścieżek wydeptanych nie przez kartografów uzbrojonych w dalmierze i heliotropy, nawet nie subtelnych historyków sztuki, lecz „zwykłych” mieszkańców i przybyszów posługujących się emocjami, wyobraźnią, pamięcią. To na nich głównie skupiona jest uwaga badawcza, którzy są często tyleż turystami, co pielgrzymami - nie tylko do miejsc kultu religijnego, lecz i do monumentów narodowych czy sanktuariów narodowych, jak Wzgórze Wawelskie; bywa, że obie te role zrastają się w nierozerwalną całość. Sacrum przyciąga zatem nie tylko za sprawą słynnych świątyń i świętych, lecz i „świętości narodowych”, których ważności nie sposób przecenić, zwłaszcza po jednej ze stron współczesnych sporów światopoglądowych, której zdarza się z narodu czynić obiekt nabożnej nieomal czci. Turystyczne peregrynacje po takich uświęconych historią narodową traktach mogą zyskać nawet walor swoistego rite de passage. Zwrócił na to uwagę John Urry, rozwijając inspirację pochodzącą od pary słynnych badaczy rytuałów Victora i Edith Turnerów:

Podobnie jak pielgrzym, turysta wyrusza z rodzimej miejscowości do odległego celu, a potem wraca do siebie. W oddalonym miejscu tak pielgrzym, jak turysta, jakkolwiek na różne sposoby, „oddają cześć” obiektowi kultu, co wprawia ich w stan uniesienia. W stosunku do turysty Victor Turner i Edith Turner mówią o sytuacjach „z pogranicza” (Urry 2007: 28).

Kraków jako narodowe sanktuarium nie jest wprawdzie miejscem bardzo odległym dla rodzimych turystów-pielgrzymów; tym bardziej dotyczy to samych mieszkańców królewskiego grodu. Ważniejsze wszakże jest to, że tworzonych przez nich map jest potencjalnie nieskończenie wiele, jak wiele jest sposobów i treści przeżywania dziedzictwa wyznaczającego charakter miejsca, jakim jest tutaj miasto będące świadkiem tysiącletniej historii. Po drodze mapy te zyskują często postać przedstawień zbiorowych naznaczonych historycznym czasem, afiliacją grupową, rozpowszechnionymi ideami i ideałami.

Tą antropologiczną wykładnię rozumienia dziedzictwa miejskiego osiągnięto nade wszystko za sprawą etnograficznych badań terenowych, skupionych na rozpoznawaniu znaczeń, wartości, idei i przeżyć, które składają się na mozaikę zsyntetyzowanych 
obrazów ludzi, miejsc i zdarzeń. Zarazem zastosowane metody badawcze pozwoliły na wskazanie cienkiej granicy pomiędzy sferą dziedzictwa a sferą sacrum, których wyodrębnianie wydaje się często zabiegiem sztucznym i nieuprawnionym. Przemawiają za tym dowody poświadczające istnienie aury niezwykłości okalającej nie tylko wiarę religijną - jej przesądzenia, postaci i atrybuty, lecz ujawniającej się również w relacjach z na pozór profanicznymi obiektami, postaciami, zdarzeniami. Dotyczy to tyleż cenionych obiektów architektury czy dzieł sztuki, co zasłużonych herosów i heroin oraz wiekopomnych czynów z ich udziałem. Rzecz to znana już od czasów Waltera Benjamina, który wprawdzie wieszczył zanik owej aury wraz z nastaniem epoki reprodukcji technicznej (Benjamin 1975). Pomylił się, gdyż wraz z niewątpliwymi procesami sekularyzacji nie zanika potrzeba transgresji i transcendencji, która może przyoblec i postać narodową. Jak zauważa Teresa Kostyrko: „Spotkanie bezpośrednie z takim przedmiotem może stać się rodzajem święta, gdyż jego bohaterem jest przedmiot auratyczny, będący niekiedy naszym osobistym sacrum" (Kostyrko 2006: 23). Oczywiście, do szeregu takich „przedmiotów” zaliczyć można i całkiem okazałe obiekty, jak Katedra Wawelska, Sukiennice czy Kopiec Kościuszki.

Stąd też w pracy znajdziemy nie tylko surową listę obiektów reprezentujących dziedzictwo Krakowa, stanowiące wszak część dziedzictwa narodowego, lecz i krótkie opisy i interpretacje, wystarczające jednak do wskazania istotnych kontekstów - historycznych, społecznych, politycznych - które owo dziedzictwo nieustannie ożywiają, zmieniają, formatują. Oto kopia posągu przedchrześcijańskiego boga (jego oryginał znajduje się w krakowskim Muzeum Archeologicznym), Światowida, stojąca u stóp Wawelu, bywa dekorowana barwami narodowymi - przykład najnowszych praktyk wyrażających postawy narodowe, na które wskazuje wspomniany już Tim Edensor w dziele o znamiennym tytule Tożsamość narodowa, kultura popularna i życie codzienne; ten sam posąg innym zaś razem staje się obiektem związanym z praktykami neopogańskimi. Z kolei kościół św. św. Piotra i Pawła stał się w ostatnich latach trzecią krakowską, a zrazem polską nekropolią - miejscem pochówku osób zasłużonych dla kraju. Inskrypcje lokalnego dziedzictwa znajdziemy nawet na długopisie, którym odwiedzający wspomnianą wystawę mogli wpisać swoje uwagi w książce gości: drewnianym, z wypaloną sylwetką kościoła Mariackiego, zwieńczonym stylizowaną głową odzianą w tradycyjną czapkę krakuskę. Jak w soczewce widać, w tym i w innych przykładach, misję dziedzictwa - jak uważa Barbara Kirshenblatt-Gimblett (1988) - refleksyjnego przyjmowania wybranych elementów przeszłości i tworzenia z nich nowych jakości. Zarazem owo dziedzictwo może wyrażać niepozorny, całkiem współczesny długopis, co narodowa nekropolia, jaką jest krypta Katedry Wawelskiej.

Lokalne dziedzictwo swe bogactwo ujawnia już na poziomie mikro, co dotyczy nie tylko owego długopisu, lecz obiektów mocniej osadzonych w krakowskim krajobrazie, jak choćby szopek krakowskich, które znajdują się na Liście niematerialnego dziedzictwa kulturowego UNESCO. To najnowsza światowa wizytówka miasta o stosunkowo 
młodej metryce, która jest nie lada atrakcją dla turystów, lecz jej fenomen wzbudza również ciekawość artystów i badaczy, a nawet postaci reprezentujących obie profesje. Należała do nich także nieodżałowana Anna Szałapak, etnografka i gwiazda Piwnicy pod Baranami, również miejsca lokalnego, szczególnego dziedzictwa, która poświęciła szopkom obszerną monografię (Szałapak 2012). Lecz znajdziemy tutaj i stare pieczęcie parafialne, księgi i naczynia liturgiczne, plany miasta zmieniającego się wraz z upływem stuleci czy zdjęcia wiekopomnych wydarzeń historycznych. Materialnym, wizualnym i społecznym podłożem lokalnego dziedzictwa są nawet buty ze studniówki lub chusty rezerwistów - rytualne atrybuty współczesnej obrzędowości. Obaj ci reprezentanci kultury materialnej nie przypadkiem zostali uwzględnieni i w książce, i na towarzyszącej wystawie, gdyż należą do szeregu obiektów o wyjątkowym znaczeniach i funkcjach interesujących badaczy kultury (Szumowska 2005; Czachowski 1997). Z kolei poziom makro to na przykład kościół Mariacki, który jest zresztą najczęstszą inspiracją dla twórców wspomnianych szopek. Jest też miejsce dla innych obiektów o podobnej skali, które bywają świadkami zdarzeń tragicznych, jak żydowski dom modlitwy przy ulicy Grodzkiej - częściowo zniszczony w czasie II wojny światowej. Dziś zamknięty i niedostępny, jest - wprawdzie niewidocznym - świadkiem wstydliwego oblicza stosunku wobec dziedzictwa społeczności żydowskiej, które pozostaje wciąż nie dość zadbane i zaopiekowane.

Ten krajobraz kulturowy, uchwycony za pomocą zmiennoogniskowego spojrzenia „kronikarza współczesności”, jak o antropologu pisał sam Bronisław Malinowski (1981), odsłania również różne, obecne tutaj tradycje religijne: katolicką, protestancką (na nieodległych ulicach także świątynie obrządku wschodniego), żydowską, w czym pomocne są zdjęcia licznych wnętrz świątyń różnych wyznań i denominacji. Jeśli do tych wnętrz zajrzeć, dostrzeżemy w nich bogatą ikonografię i odprawiane obrządki, intonowane pieśni religijne i wznoszone zbiorowo lub w skrytości ducha modlitwy. Oczywiście w krajobrazie „drugiego Rzymu” dominuje krzyż, zwieńczający kopuły kościołów na Trakcie Królewskim, ale i poza nim, wskazując na obecność świątyń, również tych najnowszych i najsłynniejszych, jak sanktuaria Bożego Miłosierdzia i Jana Pawła II w Łagiewnikach. Tym ostatnim świątyniom, oddziałującym tyleż lokalnie, co globalnie, osobną uwagę poświęca zresztą w swych badaniach jedna z redaktorek książki o dziedzictwie miejskim Krakowa - Anna Niedźwiedź (2017). Do tego można by dodać krzyże licznych kapliczek, krzyże upamiętniające walkę narodowowyzwoleńczą, krzyże-cenotafy stawiane w miejscach śmiertelnych wypadków drogowych - oddolne formy stanowienia sacrum.

Nie sposób wypowiadać się na temat wydawnictwa bez odniesienia do wspomnianej wystawy, która zdecydowała o treści i formie książki. Nade wszystko widoczny jest w niej zamysł autorski, który z bogactwa lokalnego dziedzictwa postanowił wybrać jedynie część, choć znaczącą i wyjątkową pod wieloma względami, całości lokalnego dziedzictwa. Ten rodzaj bardziej rozbudowanego katalogu, w którym opisy i interpretacje 
przedstawionych obiektów, praktyk, problemów wychodzą poza zdawkowe podpisy, może służyć za książkowy odpowiednik wystawy tym, którym nie dane było jej zobaczyć. Natomiast zamysł wystawienniczy, głównie poprzez wielkoformatowe zdjęcia fragmentów miasta (ciągów ulicznych fotografowanych z „żabiej” perspektywy, z różnych czasów), wnętrz podwórek, zaułków, eksponowanych budynków stwarzał na ekspozycji wrażenie znajdowania się w samym środku miasta i jego esencji, a równocześnie obcowania z drobiazgami i gigantami jego dziedzictwa. Być może książka Mapy miasta. Dziedzictwa i sacrum w przestrzeni Krakowa okaże się nowatorską propozycją wydawniczą, łączącą walory wizualne wystawy muzealnej z pogłębioną narracją autorską, wykraczającą dalece poza katalogowe opisy. Czas pokaże, czy tak się stanie.

\section{Bibliografia}

Benjamin W. (1975). Dzieło sztuki w dobie reprodukcji technicznej. W: W. Benjamin, Twórca jako wytwórca (przeł. J. Sikorski), (s. 66-105). Poznań: Wydawnictwo Poznańskie.

Czachowski, H. (1997). Pamiątka z wojska Opowieść o życiu prawdziwego mężczyzny. Katalog wystawy pamiątek żołnierskich z XIX i XX wieku. Toruń: Muzeum Etnograficzne im. Marii Znamierowskiej-Prüfferowej w Toruniu.

Edensor, T. (2004). Tożsamość narodowa, kultura popularna i życie codzienne (przeł. A. Sadza). Kraków: Wydawnictwo Uniwersytetu Jagiellońskiego.

Kirshenblatt-Gimblett, B. (1998). Destination Culture: Tourism, Museum, and Heritage, Berkeley: University of California Press.

Kostyrko, T. (2006). Dzieło sztuki w muzeum i jego aura. W: M. Popczyk (red.), Muzeum sztuki. Od Luwru do Bilbao (s. 21-26). Katowice: Muzeum Śląskie.

Lowenthal, D. (2013). The Past is a Foreign Country. Cambridge: Cambridge University Press.

Malinowski, B. (1981). Argonauci Zachodniego Pacyfiku. Relacje o poczynaniach i przygodach krajowców z Nowej Gwinei. Dzieła, t. 3 (przeł. B. Olszewska-Dyoniziak, S. Szynkiewicz). Warszawa: PWN.

Niedźwiedź, A. (2017). Framing the Pope Within the Urban Space: John Paul II and the Cityscape of Kraków. W: V. Hegner, P.J. Margry (red.), Spiritualizing the City: Agency and Resilience of the Urban and Urbanesque Habitat (s. 81-101). Abingdon-New York: Routledge.

Niedźwiedź, A., Kajder, K. (red.) (2020). Mapy miasta. Dziedzictwa i sacrum w przestrzeni Krakowa. Kraków: Wydawnictwo Libron.

Prown, J.D. (2000). The Truth of Material Culture: History or Fiction? W: J.D. Prown, K. Haltman (red.) American Artifacts. Essays in Material Culture (s.11-27). East Lansing: Michigan State University Press.

Szałapak, A. (2012). Szopka krakowska jako zjawisko folkloru krakowskiego na tle szopki Europejskiej. Kraków: Muzeum Historyczne Miasta Krakowa.

Szumowska, J. (2005). But w butonierce, czyli o historii i symbolice obuwia słów kilka W: M. Krajewski (red.), W stronę socjologii przedmiotów (s. 49-68). Poznań: Wydawnictwo Naukowe Uniwersytetu im. Adama Mickiewicza w Poznaniu.

Urry, J. (2007). Spojrzenie turysty (przeł. A. Szulżycka). Warszawa: PWN. 


\section{Streszczenie}

Tekst omawia książkę zredagowaną przez Annę Niedźwiedź i Kaję Kaider na temat przenikających się sfer dziedzictwa kulturowego i sacrum Krakowa. Autorzy książki skupiają się na materialnym dziedzictwie miejskim, które wciąż zdaje się niedocenianym zasobem przeszłości. W prezentowanym antropologicznym jego rozumieniu obiekty materialne nie tylko ujawniają całą gamę znaczeń służących kształtowaniu się genius loci miasta i związanych z tym tożsamości mieszkańców i przybyszów, lecz również walor poznawczy w ściśle historycznym wymiarze. Pod antropologicznym szkiełkiem i okiem okazałe budowle i drobne pamiątki zyskują wagę równą pisanym źródłom historycznym, tytułowe zaś dziedzictwo i sacrum ukazują swą nierozerwalną jedność. Na uwagę zasługuje również fakt, że książka jest drukowanym odpowiednikiem wystawy na ten sam temat, która miała miejsce w krakowskim muzeum etnograficznym.

Słowa klucze: Kraków, dziedzictwo kulturowe, sacrum, mapy miasta

\section{Summary}

The text discusses a book, edited by Anna Niedźwiedź and Kaja Kaider, on the interpenetrating spheres of cultural heritage and the sacred of Krakow. The authors of the book focus on the material urban heritage, which still seems to be an underrated resource of the past. In the presented anthropological understanding of it, material objects not only reveal a whole range of meanings that help shape the city's genius loci and the identities of its inhabitants and visitors associated with it, but also constitute a cognitive value in a strictly historical dimension. Under an anthropological scrutiny, stately buildings and small souvenirs gain an importance equal to that of written historical sources, while the titular heritage and the sacred show their unbreakable unity. It is also noteworthy that the book is a printed equivalent of an exhibition on the same subject that took place in the Krakow ethnographic museum.

Keywords: Kraków, cultural heritage, sacrum, maps of the city 
